\title{
Attitudes, Confidence in Practices and Perceived Barriers Towards the Promotion of Tobacco Cessation among Clinical Dental Undergraduates in Sri Lanka
}

\author{
R M Sumudu Himesha B Medawela ${ }^{1}$, Dugganna Ralalage D L Ratnayake ${ }^{2}$, L K \\ Nadeesha Premathilake ${ }^{3}$, Ruwan Duminda Jayasinghe ${ }^{4}$
}

${ }^{1}$ Department of Oral Medicine and Periodontology, Faculty of Dental Sciences, University of Peradeniya, Sri Lanka. ${ }^{2}$ Specialist Trainee in Community Dentistry Provincial director of Health Services Office, Central Province, Sri Lanka. ${ }^{3}$ Department of Community Dental Health, Faculty of Dental Sciences, University of Peradeniya, Peradeniya, Sri Lanka. ${ }^{4}$ Department of Oral Medicine and Periodontology, Faculty of Dental Sciences, University of Peradeniya, Peradeniya, Sri Lanka.

\begin{abstract}
Introduction: This study aimed to assess attitudes, confidence in practices and perceived barriers toward the promotion of tobacco cessation in the dental setting among clinical dental students in Sri Lanka. Methods: Role of dental schools on moulding future dental professionals with regards to education on tobacco cessation promotion is remarkable. A cross-sectional descriptive study was conducted on all the dental students from clinical years in 2018 using a self-administered structured questionnaire. Ninety-four per cent of the dental students from clinical years of faculty of dental sciences, University of Peradeniya, Sri Lanka completed the questionnaire $(65 \%$ Females and $35 \%$ Males) with a mean age of $24.65+2.24$ years. Results: Clinical dental students possessed positive attitudes towards the professional responsibility of dentists in tobacco cessation whilst only $34 \%$ strongly agreed counselling offered in the dental setting has an impact on the same. More than half of the students remained neutral or disagreed the fact that nicotine replacement is within the scope of dentistry. Respondents expressed their confidence in tobacco cessation counselling. They identified "patients' disinterest in receiving advice" as the main barrier to perform tobacco cessation practices in the dental setting. It is prudent to include formal education on tobacco cessation to the undergraduate curriculum of dental students to alleviate misconceptions related to practices of tobacco cessation in dental settings. Conclusion: It is of prime importance to identify training needs related to tobacco cessation promotion among dental undergraduates and compose a separate training module for them.
\end{abstract}

Keywords: Dental Undergraduates- Sri Lanka- attitudes- confidence in practices and barriers towards- Tobacco cessation

\section{Introduction}

Health care organizations have recognized 'tobacco' as a major global health hazard. The health care providers have been in continuous search of effective modes to educate the patients on health risks of tobacco use and to promote tobacco cessation. A popular mode of such interventions is to conduct a tobacco cessation programme for all tobacco users by primary care clinicians including oral health professionals [1]. Despite the continuous innumerable interventions, such programmes failed to achieve satisfactory results in the battle against tobacco. The widespread acceptance of tobacco use interventions in the dental setting has lagged and limitations exist [2]. Three domains namely attitudes, confidence and barriers to behavioural change are thought to play a role in determining the extent to which clinicians implement clinical practice guidelines [3].

Tobacco is consumed in many different forms, though cigarette smoking is the most prevalent form of its use 
[4]. Among the smokeless tobacco products, the most written about is betel quid mixture with added tobacco [4]. Besides, commercially prepared smokeless tobacco products such as Gutka, Toombak, Nass, Naswar, Zardaare are popular in use [5]. Consumption of tobacco in any form has accounted for an alarming figure of more than eight million deaths every year and a major proportion of them are preventable with appropriate interventions [6].

There is weighty evidence that tobacco consumption has considerable impact on oral health and in particular, increased prevalence and severity of periodontal diseases, oral candidosis and oral malignancies are associated with tobacco consumption [7-10]. According to the most recent report of the National cancer incidence data of Sri Lanka, lip and oral cavity cancers take second in the list of most common cancers in the country with an age-standardized incidence of 7.2 per 100,000 population. And also, it is reported to be the commonest cancer among Sri Lankan males [11].

Dental undergraduates are the future of the dental profession. A greater proportion of their knowledge, attitude and practice related to tobacco cessation promotion are acquired during their undergraduate training. Reason for inadequate success in the tobacco cessation programmes may exist at their exposure to their initial training. These should be intervened and barriers to these activities should be identified in order to upgrade the Sri Lankan health care system. Hence, this study was conducted to visit back to the square one and identify perceived barriers toward the promotion of tobacco cessation in the dental setting among clinical dental undergraduates in Sri Lanka.

\section{Materials and Methods}

This is a cross-sectional descriptive study conducted among the dental undergraduates undergoing clinical training at the Faculty of Dental Sciences, University of Peradeniya (In 2018). A self-administered structured questionnaire was used in the survey. The questionnaire consisted of three major sections to assess the attitudes, confidence level of practice and barriers to practice. Factors such as the age, gender, ethnicity, personal experience of tobacco use, family experience of tobacco use and experience in formal education on tobacco cessation during the training period were surveyed under demographic data.

To assess the individual attitudes toward the promotion of tobacco cessation, a fourteen-items scale was adapted from a survey conducted by Victoroff and coworkers among dental undergraduates from America [12]. These items had focused on the main three areas, professional responsibility, the scope of dental practice and effectiveness of the practice of dental professionals towards tobacco cessation. Each item consisted of a statement and a five-point Likert scale, ranging from strongly agrees to strongly disagree. The next section of the questionnaire consisted of eleven closed items based on the survey developed by the US National Dental Tobacco-Free Steering Committee to assess adherence to the four 'A's model of cessation advice (Ask, Advise, Assist and Arrange for follow up) [13]. These items were modified to adapt to the existing protocols of the curriculum of the dental undergraduates of the country and was used to assess the confidence level of practice in tobacco cessation. Perceived barriers for practices related to tobacco cessation promotion were assessed through six items in which the answers to be given in a Likert scale and was based on previous surveys published in the literature [13-15]. The questionnaire was pre-tested among a convenient sample of dental undergraduates who have just completed their resident ship and were awaiting final exam results, and it was modified accordingly.

The administrative clearance for data collection was obtained from the Dean, Faculty of Dental Sciences while the ethical clearance to conduct the survey was obtained from the Ethics Review Committee of the Faculty of Dental Sciences, University of Peradeniya. The data were analysed using the statistical software SPSS (17.00). Descriptive statistics were generated for all the questions.

\section{Results}

Hundred and fifty clinical dental undergraduates participated in the study and 94\% of the students completed the questionnaire. Among them a majority of $65 \%$ were females and the participants were within a mean age + SD of $24.65+2.24$ years. The ethnic composition of the sample consisted majority of Sinhalese (75\%), followed by Tamils (14\%), Muslims (10\%) and others (1\%) respectively. Among the clinical students, $96 \%$ of them had never consumed tobacco, while $2 \%$ had consumed tobacco in the past and $2 \%$ of them reported that they consume tobacco currently. Fifty-six per cent of the participants reported that none of their family members had consumed tobacco ever; while $26 \%$ reported that their family members consume tobacco at present. Majority of the students (74\%) stated that they had experienced a formal education on tobacco cessation during the training.

Responses to the items related to participants' attitude toward tobacco cessation are shown in Table 1. Almost all the respondents agreed that the responsibility of educating the patients about the oral health risk of tobacco consumption falls under the purview of dental professionals. Besides, majority are in agreement that the dental professionals are responsible for encouraging patients to quit tobacco use.

The majority agreed that it is within the scope of dental practice to ask about patients' tobacco use, advice patients to quit tobacco, discuss health hazards of tobacco consumption, discuss benefits of stopping and to discuss specific strategies for quitting tobacco. Only less than half of the respondents strongly agreed that prescription of nicotine gum or a transdermal patch is within the scope of dental practice. However, the abundance of responses was in favour of the fact that the referral of tobacco consumers to tobacco cessation clinics or other health care professionals is within the scope of dental practice.

Eighty-three per cent of the participants believed that 
Table 1. Responses to the Items Related to Participants' attitude Toward Tobacco Cessation

\begin{tabular}{|c|c|c|c|c|c|}
\hline & $\begin{array}{l}\text { Strongly } \\
\text { agree }(\%)\end{array}$ & $\begin{array}{l}\text { Agree } \\
(\%)\end{array}$ & $\begin{array}{l}\text { Neutral } \\
(\%)\end{array}$ & $\begin{array}{l}\text { Disagree } \\
(\%)\end{array}$ & $\begin{array}{c}\text { Strongly } \\
\text { disagree }(\%)\end{array}$ \\
\hline \multicolumn{6}{|l|}{ Professional responsibility items: } \\
\hline \multicolumn{6}{|l|}{ It is the dental professional's responsibility to: } \\
\hline $\begin{array}{l}\text { - educate patients about the risks of tobacco use related to } \\
\text { overall health and well-being }\end{array}$ & 81.30 & 18.00 & - & 0.70 & - \\
\hline $\begin{array}{l}\text { - educate patients about the risks of tobacco use related to oral } \\
\text { health }\end{array}$ & 87.30 & 11.30 & 0.70 & 0.70 & - \\
\hline - encourage patients to quit using tobacco & 78.70 & 18.00 & - & 1.30 & 2.00 \\
\hline \multicolumn{6}{|l|}{ Scope of dental practice items: } \\
\hline \multicolumn{6}{|l|}{ It is within the scope of dental practice to: } \\
\hline - ask patients if they use tobacco & 66.70 & 28.00 & 2.60 & 0.70 & 2.00 \\
\hline - advise patients to quit using tobacco & 71.30 & 26.00 & 0.70 & 0.70 & 1.30 \\
\hline - discuss the health hazards of tobacco use & 74.70 & 24.70 & 0.60 & - & - \\
\hline - discuss the benefits of stopping & 76.00 & 24.00 & - & - & - \\
\hline - discuss specific strategies for stopping & 59.30 & 34.00 & 6.00 & 0.70 & - \\
\hline - prescribe nicotine gum & 11.30 & 32.00 & 49.40 & 6.00 & 1.30 \\
\hline - prescribe nicotine transdermal patch & 6.70 & 26.70 & 56.70 & 8.70 & 1.20 \\
\hline - refer to cessation clinic or other health care professional & 39.30 & 46.00 & 11.30 & 2.70 & 0.70 \\
\hline \multicolumn{6}{|l|}{ Effectiveness items: } \\
\hline $\begin{array}{l}\text { - Tobacco cessation counselling offered in the dental office can } \\
\text { have an impact on patients' quitting. }\end{array}$ & 34.70 & 48.60 & 14.00 & 2.70 & - \\
\hline $\begin{array}{l}\text { - The dental professional's time can be much better spent doing } \\
\text { things other than trying to reduce tobacco use in patients. }\end{array}$ & 6.70 & 18.70 & 18.60 & 37.30 & 18.70 \\
\hline $\begin{array}{l}\text { - It is not worth discussing tobacco use with patients since } \\
\text { most people already know they should quit. }\end{array}$ & 5.30 & 13.30 & 12.70 & 48.00 & 20.70 \\
\hline
\end{tabular}

tobacco cessation counselling offered in the dental clinic can have an impact on quitting the habit. The majority disagreed with the statement that it is not worth discussing tobacco use with patients since most people already know they should quit. However, one-fourth of the dental students who have completed the survey alleged that the dental professional's time can be much better spent doing things other than trying to reduce tobacco use in patients.

Responses to the items assessing the confidence in tobacco cessation counselling are expressed in Table 2 . Almost all the students were confident in asking and recording the status of patients' tobacco use. Among the majority of the participants were confident in advising patients to quit tobacco in "one go" and counsel tobacco users about the negative effects of tobacco on both oral health and general health. Further, more than $85 \%$ of students were confident in counselling tobacco users about the effects of passive smoking. Surprisingly just above half of the respondents were confident in providing written information and self-help materials to the patients. It is noteworthy a considerable proportion of the students have revealed that they were not confident in prescribing nicotine replacement therapy for the patients.

Responses to the items assessing perceived barriers to provide tobacco cessation advice by dental students are presented in Table 3. Although respondents expressed their confidence in tobacco cessation counselling in the dental clinics according to the results shown in Table 2, they identified "patients' disinterest in receiving advice" as the main barrier to perform tobacco cessation practices in the dental setting. Furthermore, the lack of training in advising the patients was highlighted as a barrier in providing tobacco cessation advice.

\section{Discussion}

The detrimental effects of tobacco smoking on general health are well documented and include cancer of respiratory tract, ischemic heart diseases, stroke, hypertension, chronic obstructive pulmonary diseases, asthma and emphysema [4].

Health care settings have become increasingly attractive as an avenue for tobacco cessation and health care providers play a credible role in promoting tobacco cessation. However, widespread acceptance of tobacco use interventions in the dental clinics have lagged and limitations exist [2]. As future dentists, dental students do have an important role in promoting tobacco cessation. Hence, assessing their, attitude, practice and constraints related to tobacco cessation promotion in dental patients is important, in order to provide a better service to the country's health care system. Moreover, as the only training institution for the dental profession in the country, the Faculty of Dental Sciences, University of Peradeniya bears the highest responsibility to fill the gaps in the undergraduate curriculum by alleviating negative 
Table 2. Responses to the Items Assessing the Confidence in Tobacco Cessation Counselling

\begin{tabular}{lccc}
\hline Items measured & $\begin{array}{c}\text { Extremely } \\
\text { confident (\%) }\end{array}$ & $\begin{array}{c}\text { Confident } \\
\text { (\%) }\end{array}$ & $\begin{array}{c}\text { Not at all } \\
\text { confident } \\
\text { (\%) }\end{array}$ \\
\hline $\begin{array}{l}\text { a) Ask the patient about their smoked tobacco usage status } \\
\text { b) Proper recording of smoked tobacco usage status }\end{array}$ & 51.30 & 48 & 0.70 \\
$\begin{array}{l}\text { c) Ask the patient about their smokeless tobacco usage status } \\
\text { d) Proper recording of smokeless tobacco usage status }\end{array}$ & 54.30 & 52.70 & 3.30 \\
e) Advise patient to quit in "one go." & 48.70 & 45.30 & 6.00 \\
$\begin{array}{l}\text { f) Counsel tobacco users about the negative effects of tobacco usage } \\
\text { on their oral health. }\end{array}$ & 45.30 & 51.40 & 3.30 \\
g) Counsel tobacco users about the negative effects of tobacco usage \\
$\begin{array}{l}\text { on their general health. } \\
\text { h) Counsel tobacco users about the information on the benefits of }\end{array}$
\end{tabular}

Table 3. Responses to the Items Assessing Perceived Barriers to Provide Tobacco Cessation Advice by Dental Students

\begin{tabular}{lccccc}
\hline Items measured & $\begin{array}{c}\text { Strongly agree } \\
(\%)\end{array}$ & $\begin{array}{c}\text { Agree } \\
(\%)\end{array}$ & $\begin{array}{c}\text { Neutral } \\
(\%)\end{array}$ & $\begin{array}{c}\text { Disagree } \\
(\%)\end{array}$ & $\begin{array}{c}\text { Strongly } \\
\text { disagree }(\%)\end{array}$ \\
\hline a) Patient disinterest in receiving advice & 13.30 & 59.30 & 18.70 & 8.00 & 0.70 \\
b) Lack of training to give effective advice & 8.00 & 38.00 & 23.30 & $29.40 \%$ & 1.30 \\
c) Lack of patient education materials & 10.00 & 54.00 & 26.00 & 10.00 & - \\
d) Lack of available time during appointment & 15.30 & 50.00 & 16.00 & 17.40 & 1.30 \\
e) Respect for the freedom of the individual & 3.30 & 36.00 & 31.40 & 24.00 & 5.30 \\
f) Fear of losing patients & 1.30 & 11.30 & 18.70 & 48.00 & 20.70 \\
\hline
\end{tabular}

attitudes, gaps in practices and barriers to the promotion of tobacco cessation in Sri Lanka.

As in other studies [12], nearly all students agreed that it is the responsibility of dental professionals to educate the patients about the oral health hazards of tobacco and to encourage patients to quit tobacco use. Interestingly, the majority agreed that it is within the scope of dental practice to ask about patients' tobacco use, advice patients to quit tobacco, discuss health hazards of tobacco consumption, discuss benefits of stopping and to discuss specific strategies for quitting tobacco and refer tobacco consumers to tobacco cessation clinics. Although they agreed that it is within the scope of dentistry to discuss various strategies for quitting tobacco, a lesser percentage of them agreed to prescribe nicotine gum (43.3\%) or a transdermal patch $(33.4 \%)$, which is a common observation in the literature [12]. This was further emphasised by the fact a considerable proportion of students were not confident enough to prescribe nicotine replacement therapy for their patients. This may be since students do not view active interventions in individual's quitting efforts as a part of the dental professional's role.

When the responses regarding the effectiveness of tobacco cessation counselling are considered, it is identified that most of the students are positive about the effectiveness of tobacco cessation promotion. Nevertheless, some students may be sceptical about the extent to which this tobacco cessation promotion is effective in quitting tobacco habits.

Although the majority were confident in providing tobacco cessation counselling, less than two-thirds of the students were confident enough to provide written information to the patient. This suggests that they are sceptical about the accuracy of the information that they provide in promoting tobacco cessation. And also, about half of the respondents $(46 \%)$ identified a lack of training to give effective tobacco cessation advice as a barrier to promoting tobacco cessation. These findings suggest the need for specific training to dental undergraduates on tobacco cession promotion, in order to anticipate an effective tobacco cessation promotion in the dental setting of the country. Further, lack of patient education materials (64\%) was identified as a barrier for tobacco cessation promotion by the students. This implies the need for generating effective venue in the dental setting for tobacco cessation promotion.

The Surgeon General's Report on Oral Health in America emphasized the link between oral health and general health, and instructors should reinforce that link, encouraging students to conceive of their professional identity in a broad sense, as competent, knowledgeable, 
caring health care providers who are interested in the health behaviours that impact their patients' oral and overall well-being [16].

In conclusion, although it is identified that it is the responsibility of dental professionals to educate the patients about the oral health hazards of tobacco and to encourage patients to quit tobacco use while they seek for oral health care, widespread acceptance of pharmacological interventions such as nicotine therapy have lagged. It is of prime importance to identify training needs related to tobacco cessation promotion among dental undergraduates and compose a separate training module for them. The constraints to practice promotion of tobacco cessation should be rectified within the dental education programme for the undergraduates to produce competent dental professionals who would play a major role in combatting oral cancer and oral potentially malignant disorders in Sri Lanka.

\section{References}

1. The Tobacco Use and Dependence Clinical Practice Guideline Panel, Staff, and Consortium Representatives. A Clinical Practice Guideline for Treating Tobacco Use and Dependence: A US Public Health Service Report. JAMA: The Journal of the American Medical Association. 200006 28;283(24):3244-3254. https://doi.org/10.1001/ jama.283.24.3244

2. Warnakulasuriya S. Effectiveness of Tobacco Counseling in the Dental Office. J Dent Educ. 2002;66(9):1079-87.

3. Cabana MD, Rand CS, Powe NR, Wu AW, Wilson MH, Abboud PC, Rubin HR. Why Don't Physicians Follow Clinical Practice Guidelines? A Framework for Improvement. Pediatric Research. 1999 04;45(4, Part 2 of 2):121A-121A. https://doi.org/10.1203/00006450-199904020-00719

4. Awan K. Effects of tobacco use on oral health - an overview. Ann Dent. 2011;18(1):18-23. https://doi.org/10.22452/ adum.vol18no1.3

5. International Agency for Research on Cancer. Monographs on the Evaluation of Carcinogenic Risks to Humans - Volume 89. Smokeless Tob Some Tobacco-specific N-Nitrosamines [Internet]. 2007;89. Available from: http://monographs.iarc. fr/ENG/Monographs/vol89/mono89.pdf.

6. World Health Organization. World Health Organization Fact Sheets : Tobacco [Internet]. Available from: https://www. who.int/news-room/fact-sheets/detail/tobacco.

7. Bergström J, Eliasson S, Dock J. A 10-Year Prospective Study of Tobacco Smoking and Periodontal Health. Journal of Periodontology. 2000 08;71(8):1338-1347. https://doi. org/10.1902/jop.2000.71.8.1338

8. Tomar SL, Asma S. Smoking-Attributable Periodontitis in the United States: Findings From NHANES III. Journal of Periodontology. 2000 05;71(5):743-751. https://doi. org/10.1902/jop.2000.71.5.743

9. Johnson N. Tobacco Use and Oral Cancer: A Global Perspective. J Dent Educ. 2001;65(4):328-39.

10. Winn D. Tobacco use and oral disease. J Dent Educ. 2001;65(4):306-12.

11. Globocan Observatory W, . Cancer Today - World. Int Agency Res Cancer [Internet]. 2019;876:2018-9. Available from: https://gco.iarc.fr/today/data/factsheets/populations/900world-fact-sheets.pdf.

12. Victoroff K, Dankulich-Huryn T, Haque S. Attitudes of Incoming Dental Students Toward Tobacco Cessation
Promotion in the Dental Setting. J Dent Educ. 2004;68(5):563-8.

13. Yip J, Hay J, Ostroff J, Stewart R, Cruz G. Dental students' attitudes toward smoking cessation guidelines. Journal of Dental Education. 2000 09;64(9):641-650. https://doi. org/10.1002/j.0022-0337.2000.64.9.tb03370.x

14. Murugaboopathy V, Ankola A, Hebbal M, Sharma R. Indian dental students' attitudes and practices regarding tobacco cessation counseling. J Dent Educ. 2013;77(4):510-7.

15. Clareboets S, Sivarajasingam V, Chestnutt IG. Smoking cessation advice: knowledge, attitude and practice among clinical dental students. British Dental Journal. 2010 02;208(4):173-177. https://doi.org/10.1038/sj.bdj.2010.158

16. Rockville, MD: U.S. Department of Health and Human Services NI of D and C, Research NI of H. Oral health in American: a report of the surgeon general. 2000.

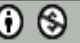

This work is licensed under a Creative Commons AttributionNon Commercial 4.0 International License. 